\title{
E-GOVERNMENT EVALUATION: REFLECTIONS ON TWO ORGANISATIONAL STUDIES
}

\author{
Stephen Jones \\ CONWY County Borough Council \\ Bodlondeb, CONWY, LL32 8DU, WALES \\ steve.jones@conwy.gov.uk \\ Zahir Irani, Amir Sharif and Marinos Themistocleous \\ Department of Information Systems and Computing \\ Brunel University, Uxbridge, UB8 3PH, UK \\ \{ Zahir.Irani. Amir.Sharif; Marinos.Themistocleous\}@brunel.ac.uk
}

\begin{abstract}
Senior executives in public sector organisations have been charged with delivering an e-Government agenda. A key emerging area of research is that of the evaluation of e-Government, given that economic factors have traditionally dominated any traditional ICT evaluation process. In this paper the authors report the findings from two interpretive in-depth case studies in the UK public sector, which explore e-Government organisational evaluation within a public sector setting. This paper seeks to offer insights to organisational and managerial aspects surrounding the improvement of knowledge and understanding of e-Government evaluation. The findings that are elicited from the case studies are analysed and presented in terms of a framework derived from organisational analysis to improve eGovernment evaluation, with key lessons learnt being extrapolated from practice. The paper concludes that e-Government evaluation is both an under developed and under managed area, and calls for senior executives to engage more with the e-Government agenda and for organisations to review eGovernment evaluation to improve evaluation practice.
\end{abstract}

Keywords: e-Government Evaluation; UK Public Sector, Interpretive Case Studies

\section{Introduction}

Electronic government (e-Government) encompasses a wide range of services - dissemination of information, commerce with the private sector, services to individual citizens and businesses and participatory democracy. Much of the motivation to develop robust e-Government infrastructures supports their search to reduce administrative bureaucracy and operational costs as well as ameliorating the services they offer to businesses, citizens and social groups [21]. Information and communications technology (ICT) is being used as a key enabler, with it [ICT] being seen as a fabric that wealds together an organisational infrastructure. According to Land [12], the introduction of ICT, including eGovernment, often means innovation and uncertainty thus leading to significant human, organisational and technical challenges. This usually leads to people changing the way they approach and undertake work. This is particularly the case with recent eGovernment initiatives, which have radically changed both the way many people work within the public sector, and how internal and external stakeholders engage with the public sector. The implementation of e-government often results in different priorities, requirements, political implications and organisational impact.

One key and current problem area is that of eGovernment evaluation. E-government is being deployed aggressively, but it not clear to what extent these organisational initiatives are being evaluated. Furthermore, in cases where these implementations are being evaluated, it is unclear what methods are being used and whether they are effective. This paper aims to explore this phenomenon. 
The paper begins with a brief literature review and an articulation of the problem area. This is followed by the research methodology. The paper continues with a brief summary of the empirical work previously presented. This is followed by an analysis of four main themes, related to the literature, that have emerged from the case studies. These themes are decision-making, evaluation methods, and comprehensive performance assessment as well as identifying practitioner concerns. Arising from the analysis of the key themes, ICT lessons have been elicited in the form of a framework with the aim of informing theory and practice. It is here where the paper seeks to make a clear contribution as in many ways ICT makes a clearer and more distinct impact on e-Government, which makes the emergence of an organisational evaluation framework timely. The paper concludes that e-Government evaluation is a under developed area and calls for senior executives to engage with the e-Government agenda and for organisations to review e-Government evaluation practice.

\section{2. e-Government Evaluation}

ICT investments are usually characterised by cost and risk, with the normative view that ICT deployment, including e-Government, should be evaluated to determine the value and benefit derived. Indeed, [28] contend that a well-documented and formal approach to investment evaluation is required to understand the implications of any ICT investment on the organisation.

Walsham [26] contends that formal mechanistic methods are the usual methods that are employed by organisations and this has been empirically confirmed by many authors [13], [1]. These methods are derived from a positivist philosophical perspective and are based upon economic factors.

The problem with this approach is that even when formal methods are applied rigorously, their relevance in the public sector domain is questionable [2]. This is because economic measures, such as added value, productivity and financial return employed are very difficult to define in the public sector [2] contends that this is particularly true with regard to ICT projects, such as e-Government, due to the complexity of defining value [18] note the position with evaluation in organisations in general and argue that:

"Evaluation is an important and complex organisational process. The traditional approach to
ICT evaluation, based on narrow technical and accounting terms, has limited relevance to the role of ICT in today's organisations. " [18], p. 94.

This is particularly true in the public sector, where these technical and business accounting terms are both difficult to define and irrelevant.

Many authors [3] [6], [28], [17], [10], [9] highlight that most organisations, especially in the public sector, have no ICT evaluation processes in place. In practice therefore, e-Government evaluation has not been given a high level of importance in organisations, and indeed is overlooked. This is perhaps not surprising; with evidence suggesting that mechanistic methods are unable to address eGovernment evaluation issues. The problem is that it not clear whether organisations evaluate egovernment, what methods are used and whether they are effective.

It is against this backdrop that the authors are seeking to increase the understanding and knowledge of e-Government evaluation and to develop a reference framework for e-Government evaluation.

Therefore, a number of human and organisational criteria that support the e-Government evaluation process need to be identified. These criteria will be integrated into an e-Government evaluation model for use by decision makers. This model will be grounded in the principles of knowledge gathering and on organisational learning. However, before such a model can be proposed, key constructs must first be generated from empirical data. A number of conditions affecting the research process now need to be addressed, with their justification for inclusion within the proposed research methodology. This is discussed in the next section.

\section{Research Methodology}

In developing a framework to construct a framework for organisational e-Government evaluation a robust methodology was followed. The terms 'research approach (or strategy)' and 'research method' are often used interchangeably. However, there is a considerable difference between the two. These terms are distinguished by the following definitions:

"A research approach (or strategy) is a way of going about one's research, embodying a particular style and employing different research methods with which to collect data." (Galliers, [4], p.147). 
Whereas,

"Research methods are simply ways to systematize observation." (Weick, [27], p. 121).

The decision to select a particular research approach is a complex one, and should only be decided after considering a number of factors and then reflecting these against the backdrop of the research question. Yin [29] poses criteria for selecting a suitable research strategy, which include:

- An identification of the type of research questions posed;

- The extent of control a researcher has over behavioural events;

- The degree of focus on contemporary events.

Although Yin [29] has identified a number of important issues, these factors should not be considered in isolation. In furtherance of the criteria identified, the authors acknowledged that the nature of the broader problem domain as well as the research domain was multidisciplinary, that is to say being focused both in social and technical terms.

The authors carefully considered these research conditions, together with Swap et al., [20] refer to as storytelling. As a result, a case-based research strategy was chosen as the most appropriate approach to use to describe the core issues associated with eGovernment evaluation in the public sector. This methodological approach used is now presented.

The research methodology applied to this research was the interpretive in-depth case study as described by Walsham [25]. The objective is to seek to understand the phenomena under study in its 'real world context'. The aim was to understand eGovernment evaluation practice. The case studies were undertaken using qualitative research methods, including informal, in-depth semi-structured interviews and participant observation. Grounded Theory as described by Glaser and Strauss [5] was used as the method for data collection and analysis of data from the interviews. Grounded Theory (GT) has a number of guidelines and procedures that help to structure and analyse data. These include seed categorising, open coding, axial coding, selective coding, theoretical sampling and constant comparison. A major component of GT is the generation of categories and the discovery of local empirical theoretical models, which are elicited from the social setting and tied to the data [23]. Conclusions or lessons can then be drawn from the theoretical models as part of the interpretive and inductive process. The focus is not analysis and prediction but rather interpreting human action and perceptions to develop an understanding of social and human aspects of e-Government evaluation.

The findings of a study of this type are local and largely indicative [25]. However, this should not be taken to imply that interpretive work is not generalisable or not that local theory may not be generally useful [25]. Generalisation from the setting is not sought, rather, the intent is to understand the deeper structure of the phenomenon under study, which may then be used to inform other settings [24] argues that the validity of the inferences drawn from one or more cases:

"does not depend on the representativeness of cases in a statistical sense, but on the plausibility and cogency of the logical reasoning used in describing the results from the cases, and in drawing conclusions from them" (Walsham [24], p. 15).

The authors decided to undertake two studies, rather than one, with the intention that the second case would provide further exploration, further richness and help generate a more substantive framework. The aim therefore was not to compare and contrast the cases, but to elicit key lessons by drawing on findings of both cases.

Figure 1 below presents the research design employed during this empirical research and is elucidated further in the paragraphs that follow. A fuller description and discussion of the GT process can be found in Urquhart [23].

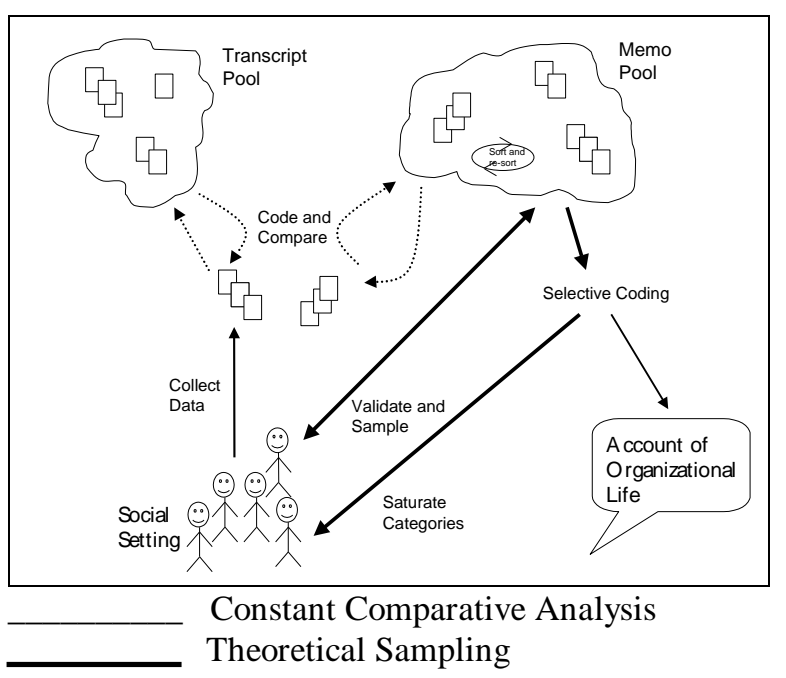

Figure 1: Grounded Theory Procedures (Hughes and Howcroft, 2000) 
The data collection procedure followed the major prescriptions of the normative literature for doing fieldwork research using GT. Primary data was used to elicit the findings presented in this paper. This data included interviews, observations, illustrative materials (e.g., current documentation, policies and procedures, e-Government strategy and other publications that form part of both case study organisational history), and archived documentation. Secondary data sources included internal reports, budget reports, and filed accounts that were later transcribed and formed the subsequent basis of qualitative content analysis [15].

One-to-one tape recorded interviews of approximately 1 hour were conducted. The interviewer carefully ensured that the interviewees were fully informed about the purpose of the interviews, and took steps to put the interviewees at ease so that a two-way, open communications climate existed. After every interview that was undertaken, notes were subsequently given to each person to check and resolve any discrepancies that may have arisen and to eliminate any interviewer bias. This approach to interviewing has proved successful in similar type of case-study research as reported by Irani et al. [11].

In the following sections the case studies are briefly described. The findings and outcomes from the studies are then presented in terms of learning.

\section{Case Studies}

This case study concerns a UK unitary local authority, which provides a range of public services, including Education, Social Services and Highways. The population is 147,000 , the staffing establishment is 6,000 , the annual revenue budget is $£ 150 \mathrm{~m}$ and the annual IT revenue budget is $£ 2.5 \mathrm{~m}$. Six senior ICT stakeholders were interviewed as part of this case study. These were the Head of IT, IT Account Manager, IT Operations Manager, Assistant Director of Finance, a senior Social Services Manager and Assistant Chief Executive.

The second case concerns another UK unitary local authority, which provides a similar range of public services, as in case study one. It has a population of 129,000 , a staffing establishment of 7,000, an overall annual revenue budget of $£ 157 \mathrm{~m}$, and an annual IT revenue budget of $£ 2.2 \mathrm{~m}$. As in the first case, up to six senior ICT stakeholders were sought to enable the research to have sufficient depth and six agreed to be interviewed to contribute to the study. These were the Head of Information, Communications and Technology (ICT), ICT Operations Manager, the Deputy County Treasurer, a senior Social Services Manager, a senior Housing Manager and a senior Finance Manager.

\section{Research Findings}

In the following sections, an analysis of the four main emergent themes that have been elicited from the empirical work - decision making, evaluation method, comprehensive performance assessment and practitioner concerns - is presented. It is important to note that findings and lessons drawn from the two case studies are not generalisable, but may be generally useful [25]. The first key emergent theme is decision making and this is discussed in the next section.

\subsection{Theme One - Decision Making}

Much of the literature on management decisionmaking subscribes to the view of the objective and rational manager [22]. However, the empirical work illustrates that decision-making with regard to eGovernment issues in the case study organisations is delegated and unsophisticated. That is to say that the decisions made with regard to e-Government are not made by senior executives but are delegated to middle managers. These important decisions, including investment decisions, are not economically based. They were described as largely 'obvious and common sense'. This resonates with the work of Bannister [2] who contends that decision-making in the public sector is not always based upon accounting and economics. The findings also resonate with the work of Introna [8] which argues that mangers are not rational decision makers but know how to act because they are always and already involved in the world.

The case studies suggest that managers often use opportunist tactics to achieve subjective outcomes and to achieve personal and professional goals, including those concerned with e-Government. Existing power relations influence discourse, action and outcomes. Professionals sometimes do not act in the interests of the organisation, but rather to an allegiance to their own professional group or industry developments and direction.

The empirical work also highlighted how people behave towards decisions that result in changing circumstances. E-Government implementations often bring a change to working practices. The case studies show that this can lead to resistance from users to 
fully utilise e-Government facilities and opportunities in the respective service area.

\subsection{Theme Two - Evaluation Methods}

According to the literature, one of the greatest challenges facing organisations is to ensure that ICT implementations, including e-Government, deliver value and, furthermore, to demonstrate this to senior executives. This is particularly true for the two case study organisations, who along with other UK Local Authorities, have been charged by national government with the task of demonstrating continuous improvement.

Formal methods for the evaluation of eGovernment in an attempt to prove best use, value and benefit is being obtained from the investment have not been used. These mechanistic methods have limited credibility, particularly with ICT practitioners, in both case studies. This growing number of well-developed methods for assessing returns (financial or otherwise), are viewed with much scepticism by ICT practitioners and key ICT stakeholders in the case study organisations. They are viewed as being essentially flawed, due to their economic bias. They are therefore, ignored and generally not used to evaluate e-Government.

In the rare instances where evaluation has been undertaken in the past using these methods, it resulted in a power and persuasion process. The outcome of the application of the mechanistic method was pre-determined to support a particular powerful stakeholder view. For example, in one organisation the Payback method was used by a vendor and financial consultants as a justification to replace a older e-Government technology platform, when infact, the main driver was the withdrawal of vendor support for the software system on the platform in question. This leads to the conclusion that the ICT evaluation technique employed was a justification mechanism not an evaluation process.

In practice, in both organisations, responsibility for evaluation and action was unclear. Service managers and users have tacitly assumed that eGovernment evaluation is the function of specialist ICT management. This finding concurs with the view of Smithson and Hirschheim, [19], who note that 'ICT evaluation is usually assumed to be the responsibility of ICT management'. This was of some concern to ICT management, who were unaware that they were deemed responsible for this aspect. It could be argued that this is not an ideal situation, as ICT management do not fully understand how eGovernment impacts upon a service area within an organisation. It is important that responsibility for the evaluating the impact of e-Government is clearly defined and articulated.

Irani and Love [10] proposed a taxonomy of ICT evaluation approaches to assist in the choice of appraisal methods. However, the problem with mechanistic ICT evaluation methods is that managers have difficulty in determining what aspect to measure, other than economic factors. Paradoxically, these economic factors seem relatively straightforward to calculate, but have little meaning in the public sector as this sector is not motivated by financial gain through profits but rather economic cost saving and value to the citizen. However, it is important in the modern organisation to assess the impact of e-Government implementations and the case study organisations suggest that this should include some form of user or stakeholder evaluation. The main perceived difficulty is the collection of 'evidence'.

There is no dedicated evaluator and no one has defined responsibility of undertaking e-Government evaluation. Due to the costs involved and the importance of gauging the impact of e-Government, the case studies recognise that a role could exist for an independent evaluation professional to facilitate discourse and undertake e-Government evaluation studies. Both organisations have not undertaken eGovernment evaluation, defined responsibility for eGovernment evaluation, reviewed the appropriateness of evaluation techniques for e-Government, or adequately resourced e-Government evaluation.

\subsection{Theme Three - Comprehensive Performance Assessment}

Despite the lack of use of evaluation methods in the two case study organisations, the empirical work illustrates that public sector ICT practitioners are coming under increasing pressure to adopt evaluation, in the from of metrics, in an attempt to benchmark and better quantify e-Government value and benefits. This should be of major concern to the two case study organisations, as prescriptive mechanistic methods for undertaking evaluation are part of the Comprehensive Performance Assessment (CPA), which is undertaken by external Government Auditors.

The Local Government Act [14] demands that public sector authorities be committed to service improvement and that service improvements must be demonstrated. CPA, therefore, is an important and current issue within the UK public sector domain. Each Authority is subject to CPA by external 
auditors. The philosophy underpinning CPA is that all Local Authorities must ensure that their business processes and services are operating well and that there is a commitment to continuous improvement. Evaluating, benchmarking and comparing local government organisational and service delivery performance are key components of CPA.

It has been suggested that it is very difficult to effectively evaluate ICT in organisations unless there is a clearly documented, systematic and formal approach to investment justification and post implementation audits [28]. However, many authors [26], [6], [10] have highlighted that there are inherent difficulties associated with quantifying estimates and the subsequent analysis.

Moreover, there is still widespread and continuing disagreement as to the factors and metrics to include in any formal, quantitative approach to eGovernment evaluation. This is the prevailing situation in both case study organisations. Indeed, the interviewees in the case study organisations have cited the difficulties in fully understanding and subsequently selecting a formal evaluation method as one of the reasons why a formal approach has been discounted. This has some repercussions because of the recent introduction of CPA.

The empirical work indicated that ICT practitioners and senior executives in the public sector are becoming increasingly concerned with this initiative and have to find ways of undertaking evaluation, including evaluation of E-Government. The case study organisations suggest that there are difficulties with using traditional formal mechanistic evaluation methods to satisfy the CPA. For example, it is difficult to evaluate an e-Government strand which aims to assist with the development of policy making, perhaps via an online Community discussion group, using mechanistic methods [1]. The case study organisations acknowledge that it is difficult to evaluate e-Government and have not addressed this issue. This presents a challenge in terms of CPA.

\subsection{Theme Four - Practitioner Concerns}

The empirical work has indicated that the lack of e-Government ownership is a major cause of concern to practitioners. There is no visible sponsorship from a senior executive for e-Government in both organisations. Strong senior management sponsorship for e-Government is key and it is also important that e-Government ownership is clearly understood [16].

ICT practitioners and internal e-Government stakeholders in both case study organisations are not concerned with the specifics of e-Government assessment metrics, detailed benefit measurement formulae or mechanistic evaluation techniques. They are concerned with the successful introduction, operation and impact of e-Government. These issues must be considered and addressed to gauge what value and benefit the organisation and associated stakeholders obtain from e-Government implementations. What is of paramount importance in both case study organisations is not whether eGovernment is cost justified, but rather to what extent it is useful and successful in practice. In organisations such as the case studies, where eGovernment evaluation procedures do not exist and stakeholder opinion is not significantly canvassed, it makes it difficult to judge the impact of eGovernment and whether it delivers value. In an era when organisations depend on the successful use of eGovernment, where large costs are involved, and where chief executives are dissatisfied with the level of return on e-Government expenditure, this prevailing situation is far from ideal.

The future challenge for practitioners is to focus on the value and impact of e-Government to the organisation, and develop evaluation approaches and procedures that can assist in this area. The empirical case study research in this paper reinforces this view and highlights that e-Government evaluation is both an under-developed and an under-managed area. The case study organisations understand that they can increasingly ill-afford to neglect evaluation due, in part, to the pressures of the CPA initiative from central government. The outcomes from the study suggest that there is a need to review the way eGovernment is evaluated and this concern is shared by practitioners.

Arising from the discussion and analysis of the four main emergent themes, lessons learnt have been elicited to help inform theory and practice. These are presented in the next section.

\section{Lessons learnt}

The lessons learnt from the e-Government evaluation case studies have been elicited from the literature and the by drawing on the empirical work. These imperatives have been developed by the authors to act as an aide-memoir to practitioners to help improve e-Government evaluation practice, as follows: 
1. Senior executives must engage with eGovernment investment decision processes to improve decision-making.

2. Organisations should consider the appropriateness and validity of evaluation techniques for e-Government to improve the understanding of the impact e-Government.

3. Organisations should consider relating notions of success other than costs, such as user satisfaction, to help evaluate and improve the understanding of e-Government implementations.

4. Organisations should adequately resource eGovernment evaluation, perhaps employing a dedicated evaluator, to ensure it is undertaken robustly.

5. Organisations should identify and articulate who is responsible for e-Government evaluation, e.g. ICT practitioner; user; organisational accountant, to clarify responsibility.

6. A senior executive should sponsor e-Government evaluation to drive and give importance to the process.

Whilst these lessons are intended to inform e-

Government evaluation, it is the action, or lack of action, of stakeholders that will influences the level success of any e-Government implementation.

\section{Conclusions}

In this paper the authors have presented the findings from two case studies that explore eGovernment organisational evaluation.

The literature and the empirical work illustrates that e-Government evaluation is extremely difficult and complex, which has far more than just an economic dimension. Undertaking e-Government evaluation is a subject that traditionally has not been given significant attention, particularly in IS practice, and it is both an under-developed and undermanaged area. However, with the growing imperatives of CPA in the UK public sector, it is an area that is gaining a high level of interest. The lessons presented in this paper should help improve e-Government evaluation practice.

Senior executives need to actively engage with the e-Government agenda and provide adequate stewardship, sponsorship, clarity of responsibility and resources to this important public sector initiative. Organisations need to review and challenge traditional ICT evaluation models based upon economic factors, because they are inappropriate for e-Government in the unique culture of the public sector. The concerns of stakeholders and the requirements of $\mathrm{CPA}$ are demanding that organisations develop e-Government evaluation approaches to address the deficiencies.

\section{Acknowledgements}

The authors acknowledge the support from the Information Systems Evaluation and Integration Group (ISEing) which supported part of this work. ISEing was established at Brunel University Department of Information Systems and Computing, in December 2000, under a research grant from the UK Engineering and Physical Sciences Research Council (EPSRC: GR/R08025/01). Financial support to present this paper will come from the EPSRC funded 'e-Government Integration and Systems Evaluation (e-GISE)’. EPSRC Ref: [GR/T27020/01].

\section{References}

1. Ballantine, J. A., and Stray, S. J., "Information Systems and Other Capital Investments: Evaluation Practices Compared", Logistics and Information Management, 12(1-2), 1999, 78-93.

2. Bannister, F., "Dismantling the Silos: Extracting New Value from IT Investments in Public Administration", Information Systems Journal, 11(1), 2001, 65-84.

3. Fountain, Jane. "Prospects for Improving the Regulatory Process Using E-Rulemaking." Communications of the ACM 46.1 (January 2003).

4. Galliers, R.D., “'Choosing information systems research approaches". Information Systems Research - Issues, Methods and Practice Guidelines, (Galliers, R.D. Ed.) Blackwell Scientific, London, 1992, 144-162.

5. Glaser, B. G., and Strauss, A., The Discovery of Grounded Theory: Strategies for Qualitative Research, Aldine, New York, 1967.

6. Hirschheim, R. A., and Smithson, S., "Evaluation of Information Systems: A Critical Assessment". In Beyond the IT Productivity Paradox 
(Willcocks, L., and Lester, S., Eds.), Wiley, Chichester, 1998.

7. Hughes, J., and Howcroft, D. A., "Grounded Theory: Never Knowingly Understood", Information Systems Review, 4(1), 2002, 181197.

8. Introna, L., Management, Information and Power, Macmillan, London, 1997.

9. Irani, Z., "Critical evaluation and integration of information systems": Invited Viewpoint. Business Process Management Journal, 8(4), 2002, 314-317.

10. Irani, Z., and Love, P.E.D., "The propagation of technology management taxonomies for evaluating investments in information systems", Journal of Management Information Systems, 17(3), 2001, 161-177.

11. Irani, Z., Jones, S., Love, P.E.D, Elliman, T., and Themistocleous, M., "Evaluating Information System Investments in Local Government: Drawing Lessons from Two Welsh Cases", Information Systems Journal, 15: (1), 2005, 6182.

12. Land, F. F., "IS Evaluation: Recent Trends", Keynote Speech, NUKAIS Information Systems Evaluation Seminar, Priestley Hall, Leeds Metropolitan University, 27th February, 2001.

13. Lefley, F., and Sarkis, J., "Short-termism and the Appraisal of AMT Capital Projects in the US and UK", International Journal of Production Research, 35(2), 1997, 341-355.

14. Local Government Act, Local Government Act for Local Authorities in England and Wales, Central Government Office, London, 1999.

15. Mayring, P., "Qualitative content analysis", Forum: Qualitative Social Research, 1(2), 2000 $1-80$.

16. National Assembly for Wales, Guidance to Local Authorities on implementing E-government Statements, National Assembly for Wales, Cardiff, UK, 2002.

17. Remenyi, D., Money, A., Sherwood-Smith and Irani, Z., Effective Measurement and Management of IT Costs and Benefits, Butterworth-Heinemann, Oxford, 2000.
18. Serafeimidis, V., and Smithson, S., "Information Systems Evaluation in Practice: a Case Study of Organisational Change", Journal of Information Technology, 15(2), 2000, 93-105.

19. Smithson, S., and Hirschheim, R. A., "Analysing Information Systems Evaluation: Another Look at an Old Problem", European Journal of Information Systems, 7(3), 1998, 158-174. .

20. Swap, W., Leonard, D., Shields, M., and Abrams, L. "Using mentoring and storytelling to transfer knowledge in the workplace", Journal of Management Information Systems, 18, 1 (2001), 95-114

21. Taft, D. K. "Raising the e-government banner", CRN, March 19, 32-38, 2001.

22. Taylor, F. W. "Scientific Management". In Pugh, D. S. (Ed.), Organisation Theory: Selected Readings, Penguin, London, 1990, 275-295.

23. Urquhart, C. "An Encounter with Grounded Theory: Tackling the Practical and Philosophical Issues", In Qualitative Research in Information Systems: Issues and Trends (Trauth, E., Ed), Idea Group Publishing, London, 2001

24. Walsham G., Interpreting Information Systems in Organizations, John Wiley \& Sons, Chichester, 1993.

25. Walsham, G., "Interpretive Case Studies in ICT Research: Nature and Method", European Journal of Information Systems 4(2), 1995, 7481.

26. Walsham, G., Interpretive Evaluation Design for Information Systems. In Beyond the IT Productivity Paradox (Willcocks, L. and Lester, S., Eds.), Wiley, Chichester, 1998.

27. Weick, K.E., "Theoretical assumptions and research methodology selection", In The information systems research challenge, Edited by McFarlan F.W., Harvard Business School, Boston, MA, 1984, 111-132.

28. Willcocks, L., and Lester, S., "Information Technology: Transformer or Sink Hole", In Beyond the IT Productivity Paradox (Willcocks, L., and Lester, S., Eds.), Wiley, Chichester, 1998.

29. Yin, R.K., Case study research: Design and Methods $2^{\text {nd }}$ Edition, Sage Publications, Thousand Oaks, CA, 1994. 
